\title{
İlginlik Kuramına Göre Düşük/Yüksek Ürün İlginliğinin Tüketiciler Tarafından Değerlendirilmesi
}

\author{
Engin Coşkun (Arş. Gör.) \\ Anadolu Üniversitesi İletişim Bilimleri Fakültesi \\ engin_coskun@anadolu.edu.tr
}

Başvuru Tarihi: 05.02.2018

Yayına Kabul Tarihi: 12.06.2018

Yayınlanma Tarihi: 30.07.2018

\section{Öz}

"İlginlik" ya da diğer adıyla "İlgilenim" kavramı köken olarak sosyal psikolojiye dayanmakla beraber ikna edici iletişim, pazarlama ve reklamcılık disiplinlerinin de temelinde yer alan bir kavram olmuştur. 1960'lı yıllarda konu ile ilgili araștırmalar yapılmaya başlanmış ve günümüzde de sürerek devam etmektedir. Bu araştırmada da ilginlik kavramından bahsedilecek ve 1960’lı yıllardan günümüz tüketicisinde ürün ilginliğini anlamında bir fark olup olmadığı kuram bağlamında değerlendirilecektir. Bu değerlendirmede Eskişehir Anadolu Üniversitesi çalışanlarına satın alma kararı ölçeği ile belirlenen ürün gruplarına yönelik olarak ürün satın almalarıyla ilişkili sorular sorulmuştur. Kaller Fay Grup ürün kategorisine göre yapılan araştırmada ürün ilginliğinin hangi üründe yüksek hangi üründe düşük olduğu ürün kategorisi bağlamında değerlendirilmiştir. Değerlendirme sonucunda; tüketicilerin en yüksek ürün ilginliği Telekomünikasyon kategorisinde, Cep Telefonu (Smartphone), en düşük ürün ilginliği ise, Alışveriş yeri kategorisinde, AVM tercihi olarak çıkmıștır.

Anahtar Kelimeler: İlginlik, Ürün İlginliği, Tüketici Değerlendirmesi. 


\title{
Evaluation of Low/High Product Involvement by Consumers According to Involvement Theory
}

\author{
Engin Coşkun (Res. Asst.) \\ Anadolu University Faculty of Communication \\ engin_coskun@anadolu.edu.tr
}

Date Received: 05.02.2018

Date Accepted: 12.06 .2018

Date Published: 30.07.2018

\begin{abstract}
The concept of "interest" based on persuasive communication, marketing and advertising disciplines as well as rooted in social psychology. In the 1960's, research on the subject started and it continues today. In this research, the concept of involvement will be mentioned and it will be evaluated from the 1960s on the theory that there is a difference in product involvement in today's consumer. In this evaluation, questions were asked to Eskişehir Anadolu University employees about purchasing products for the product groups determined by the purchase decision scale. According to Kaller Fay Group product category, the product category in which the product interest is high and which is low is evaluated in the context of the product category. At the end of the evaluation; Consumer's highest product involvement; In the telecommunication category, Mobile Phone (Smartphone), in the lowest product involvement, in Shopping category, preference of Shopping Mall.
\end{abstract}

Keywords: Involvement, Product Involvement, Consumer Evaluation. 


\section{Giriş}

İlginlik kavramı 1960’lı yıllardan günümüze kadar geçen sürede birçok farklı disiplin tarafından incelenmiş, üzerine birçok araştırma yapılmış bir kavramdır. İngilizce karşılığı "involvement" olan kavram, dilimize "ilginlik", "ilgilenim" ya da "katılım" olarak çevrilmiştir.

Kavram, ilk olarak sosyal psikoloji alanında yapılan araştırmalar sonucu ortaya çıkmıştır. İnsan davranışlarına etki eden unsurlardan birisi olan tutum araştırmaları bağlamında Sherif ve diğerlerinin ilginliği sosyal yargı kuramına bağlamaları ve "sosyal ve kişisel bir duruma yönelik tutum" olarak nitelemeleriyle kavram șekillenmeye başlamıștır. Bunun dıșında ilginliği, Eagly ve Chaiken tutum ile ilişkilendirmektedir. Tutum, "bir şeyi belli oranda olumlu ya da olumsuz olarak değerlendirerek ifade edilen psikolojik bir eğilimdir" ve tutumun bilișsel, duygusal ve davranışsal olmak üzere üç boyutu vardır (Ulusu, 2016, 569-586). Bu üç boyut ikna edici iletişimin oluşması için oldukça önemli olan boyutlardır.

$\mathrm{Bu}$ çalışmada, ilginlik kavramından bahsedilecek, ilginlik kavramının geçirdiği tarihsel evre üzerinde durulacak ve Krugman'ın geliștirmiş olduğu “Düşük/Yüksek ilginlik modeli” kullanılarak tüketicilerin ürün ilginliklerinin değerlendirilmesi amaçlanmaktadır.

\section{Ilginlik Kavramı ve Krugman'ın Düşük/Yüksek Ilginlik Modeli}

İlginlik kavramının sosyal psikoloji alanında kavramsal olarak yapılanmaya başlaması özellikle 1965-1980 yılları arasında sosyal bilimlerin insan davranış ve tutumlarıyla yakından ilişkili pazarlama, tüketici davranışı ve reklam alanlarında da farklı boyutlarıyla ele alınmasına ve tartışılmasına neden olmuştur (Ulusu, 2016, 569-586). Bu anlamda birçok disiplin kendi araçları ve amaçları doğrultusunda kavramı ele almış ve bu kavramı çeșitli araştırmalarda, özellikle "tutumlar" bağlamında kullanmışlardır. Literatür genel olarak incelendiğinde birbirinden farklı tanımlarla karşılaşmak mümkündür. Hirschman (1970) ilginliği; tüketicilerin kendi deneyimlerini ifade etmeleri, davranıșın sönmesi ya da marka ile ilişkilerin geliştirilmesi olarak açıklamaktadır. (Doorn ve diğerleri, 2010, 254). Antil (1984) tarafından yapılan bir araştırmada da literatür incelenmiş ve ilginlik kavramıyla ilgili olarak birçok farklı tanımının olduğu ortaya çıkmıştır. Bu tanımlara bakıldığında; Krugman'a göre "İzleyicinin bir dakika içerisinde kendi yaşamı ile uyarıcı arasında bilinçli olarak kurduğu köprü, ilişki, bağlantı ya da kişisel referans sayısı”, Day’e (1970) göre "bireyin ego yapısının odağındaki nesnelere yönelik genel ilgi düzeyi", Bowen ve Chaffe'ye (1974) göre "tüketicinin üründen beklediği potansiyel fayda ya da ödül”, Robertson'a (1976) göre "tüketicinin ürün/markaya yönelik inanç sisteminin gücü", Houston ve Rothschild'e (1978) göre "Bir ruhsal durum değişkeni olarak tanımlandığı, Mitchell'e $(1979,194)$ göre ilginlik "belirli bir uyaran veya durum tarafından harekete geçirilen ilgi, uyarılma ve motivasyon miktarını ifade eden içsel durum değişkeni" olduğu görülmektedir. Tüketicinin uyaranlar karşısında güdülenmesiyle ilgili bir duruma sürekli ilginlik denilmekte, tüketicinin bir ürüne gösterdiği duruma bağlı olmayan, uzun vadeli ilgisi ve düşkünlüğü ise durumsal ilginlik olarak değerlendirilmektedir. Tüketicinin satın alma sonucunda yüksek menfaatler söz konusu ise satın alma gerçekleşene kadar bir ürüne/hizmete karşı olan geçici ilgisi de mesaja karşı gösterilen tepki ilginliği olarak tanımlanmaktadır (Ulusu, 2016, 569-586). Reklamın kendisini veya reklamdaki ürünle ilgili mesaja 
karşı kişinin hissettiği uyarılma ve güdülenme hali Krugman’a (1965) göre, geçici bir ruhsal durum değişkenidir ve tüketicinin uyaranlar karşısında duyduğu geçici uyarılma halidir. Lastovicks'e (1979) göre ürünlere göre ilginlik düşük ve yüksek olmaktadır. "Düşük ilginlik ürünleri sınıfında tüketici kişisel değerleriyle ürün arasında düşük ya da hiç bağ kurmaz, bu yüzden tüketicide ürüne bağlılık ya çok azdır ya da hiç yoktur." Petty ve Cacioppo'ya (1981) göre "Yüksek ilginlik durumunda mesajların merkezi yol izlenerek takip edildiği varsayılır ve mesajların algılanışı daha çok bilgiseldir. Düşük ilginlik durumunda ise çevresel yol takip edilir ve mesajların geçerliliği çevresel yolda verilen sembolik değerler, logo, müzik, ses vb. öğelere göre belirlenmektedir. Bloch'a (1981) göre "Ürünün kișide meydana getirdiği ilgi, uyarılma miktarı ya da kişinin ürünle kendisi arasında gözlemlenemez bir duygusal bağlantı kurması halidir."

Kavramın bu denli yoğun bir şekilde ele alınması ve kavramın farklı tanımlamalarının oluşması neticesinde uzmanlar bu kavramı sınıflama yoluna gitmişlerdir. Sınıflama Muehling ve diğerleri $(1993,23-34)$ tarafından oluşturulmuş ve ilginlik kavramının;

- Kişiye göre bir durum olduğu,

- Kişiye göre bir özellik olduğu ve

- Bir süreç olduğu şeklinde sınıflandırma yapmışlardır.

Andrews ve diğerlerinin yapmış oldukları araştırmada $(1990,32)$ ise, kavram üzerine yapılan araştırmalar üzerine yoğunlaşarak ve bir kavram araştırmaları sınıflaması oluşturulmuştur. Buna göre;

- Dikkat ve Bilgi İşleme Stratejileri

- İzleyici İlginliği Araştırmaları

- Durumsal İlginlik ve Ürün İlginliği Çalışmaları

- Satın alma ya da mesaj işleme noktasında aracı bir değişken olarak gören araştırmalardır.

İlginlik üzerine yapılan araştırmalarda özellikle düşük ilginlikte öğrenme kavramını literatüre kazandıran ve ilginlik çalışmalarında öncü olarak sayılan Krugman'a göre ilginlik, izleyicinin bir dakika içerisinde kendi yaşamı ile uyarıcı arasında bilinçli olarak kurduğu köprü, ilişki, bağlantı ya da kişisel referans sayısı" dır. Krugman'ın yayınladığı "Televizyon Reklamlarının Etkisi: İlginlik Olmadan Öğrenmek" isimli makalede ilginliğin basılı mecralarda TV reklamlarına göre daha etkili olduğunu savunmaktadır. Bunu da basılı mecra reklamlarının izleyicilere daha fazla özgürlük tanımasına bağlamaktadır. TV reklamlarının ise reklam verenin göstermek istediği, vurgulamak istediği noktaya vurgu yaptığı dolayısıyla kısıtlı bir süre içerisinde izleyicinin özgürlüğünü kısıtladığı üzerinde durmaktadır. Ayrıca kitle iletişim araçlarının ilginlik üzerindeki etkisine de değinilmiştir.

Düşük İlginlik Modeli” ne göre ilginliğin yüksek ve düşük seviyeleri vardır. Yüksek ilginlik, tüketicileri alternatifler hakkında bilgi aramaya, alternatifleri değerlendirirken elde edilen bilgiyi kullanmaya ve karmaşık bir karar verme süreci yaşamaya iter. İlginlik düşükse ürün ya da hizmetler hakkında bilgi arama daha az gerçekleşir ve tüketici daha çok marka, logo, ambalaj, reklam müziği gibi çekici unsurlara dikkat etmektedir. Düşük ilginlik durumunda ikna etkisi daha yavaş olacağından reklamların tekrar edilmesi gerekmektedir. (Ulusu,2016,575).

Krugman'ın düşük/yüksek ilginlik modeline ek olarak Richard Vaugnn'un (1980) önerdiği modelde ürünleri kategorize etmede Krugman'ın kategorileri kullanılmış 
fakat Krugman'ın modeline ek olarak düşük ya da yüksek ilginliğe düşünme ve hissetme kavramlarını da eklemiştir. Bu kavramlara göre reklam mesajına maruz kalan tüketiciler ürün kategorilerine göre düşünerek ya da hissederek davranabilirler. FCB ızgarası olarak adlandırılan bu modelde de Krugman'ın "düşük/yüksek ilginlik" yaklaşımından yola çıkılmıştır.

Krugman'ın düşük/yüksek ilginlik modelinde Andrews ve diğerlerinin yapmış oldukları (1990) ilginlik araştırmaları sınıflandırmasında yer alan "Satın alma ya da mesaj işleme noktasında aracı bir değişken olarak gören araştırmalar" kapsamında değerlendirilmektedir. Bu bağlamda Krugman'ın düşük/yüksek ilginlik modeli satın alma kararı ile doğrudan ilişkilidir. Çünkü önermiş olduğu ürün kategorilerinde yer alan ürünlerin tüketiciler tarafından satın alma kararı bağlamında değerlendirilen bir yargıya varılmaktadır.

\section{Yöntem}

Bu çalışmada, Krugman'ın (1965) düşük/yüksek ilginlik modeli üzerinden hareketle Mittal (1994) tarafından geliştirilen ve satın alma kararı ilginliği ölçeği kullanılmıştır. $\mathrm{Bu}$ anlamda tüketicilere satın almış oldukları ürünler bağlamında nicel araștırma yöntemlerinden olan "ölçek" kullanılarak bir değerlendirme yapılmıştır. Bu anlamda kullanılan ölçek aşağıdaki gibidir:

Tablo 1: Satın Alma Kararı İlginliği Ölçeği

\begin{tabular}{|l|l|l|}
\hline SAKI 1 & $\begin{array}{l}\text { Bu ürünün piyasada mevcut olan tür } \\
\text { ve markalar arasında seçim yaparken } \\
\text { hangisini alacağımı hiç düşünmem. }\end{array}$ & $\begin{array}{l}\text { Bu ürünün piyasada mevcut olan tür } \\
\text { ve markalar arasında seçim yaparken } \\
\text { hangisini alacağımı iyice düşünürüm. }\end{array}$ \\
\hline SAKi 2 & $\begin{array}{l}\text { Bu ürünün piyasada mevcut olan } \\
\text { farklı markalarının birbirine çok } \\
\text { benzer olduğunu düşünürüm. }\end{array}$ & $\begin{array}{l}\text { Bu ürünün piyasada mevcut olan } \\
\text { farklı markalarının birbirinden çok } \\
\text { farklı olduğunu düşünürüm. }\end{array}$ \\
\hline SAKi 3 & $\begin{array}{l}\text { Bu ürünle ilgili doğru bir seçim yapmak } \\
\text { benim için hiç önemli değildir. }\end{array}$ & $\begin{array}{l}\text { Bu ürünle ilgili doğru bir seçim } \\
\text { yapmak benim için çok önemlidir. }\end{array}$ \\
\hline SAKi 4 & $\begin{array}{l}\text { Bu ürünü satın alırken yaptığım } \\
\text { seçim hakkında hiç endişelenmem. }\end{array}$ & $\begin{array}{l}\text { Bu ürünü satın alırken yaptığım } \\
\text { seçim hakkında çok endişelenirim. }\end{array}$ \\
\hline *Satın alma kararı ilginliği, "SAKI" olarak kısaltılmışırı. & \multicolumn{2}{|l}{}
\end{tabular}

Kaynak: Mittal, 1989.

Ölçeğin orijinali 7'li likert tipi ölçektir. Ölçek 5'li likert tipi cevap alınmasına göre uyarlanmıştır. Uyarlanmasının sebebi 7'li likert ölçekte yer alan aralıkların bu kullanılan ürün satın alma kararı ve ürün ilginliği anlamında anlamlı sonuçlar vermeyeceği, aralıkların daha belirgin olması ise daha anlamlı sonuçlar vereceğinden dolayıdır (Norman, 2010: 625-632). Dolayısıyla aralıklar (intervals) yeniden düzenlenmiş ve ölçeğin orijinalinde yer alan aralık basamakları da yeniden düzenlenmiştir. 5’li likert tipine göre düzenlenen aralıklar aşağıdaki gibidir:

Her 4 soruya da karşılık gelen aralıklar sırasıyla:

SAKİ 1: Hiç düşünmem (1.00-1.79), Düşünmem (1.80-2.59), Ne düşünürüm ne düşünmem - kararsızım (2.60-3.39), Düşünürüm (3.40-4.19), İyice düşünürüm (4.20-5.00). Buna göre 1.00 ile 3.39 arası düşük ilginlik seviyesi, 3.40-5.00 arası yüksek ilginlik seviyesidir.

SAKİ 2: Çok benzer olduğunu düşünürüm (1.00-1.79), Daha az benzer olduğunu düşünürüm (1.80-2.59), Ne benzer olduğunu düşünürüm ne farklı olduğunu düşünürüm - kararsızım (2.60-3.39), Farklı olduğunu düşünürüm (3.40-4.19), Çok 
farklı olduğunu düşünürüm (4.19-5.00). Buna göre 1.00 ile 3.39 arası düşük ilginlik seviyesi, 3.40-5.00arası yüksek ilginlik seviyesidir.

SAKİ 3: Hiç önemli değildir (1.00-1.79), önemli değildir (1.80-2.59), ne önemlidir ne önemli değildir - kararsızım (2.60-3.39), önemlidir (3.40-4.19), çok önemlidir (4.20-5.00). Buna göre 1.00 ile 3.39 arası düşük ilginlik seviyesi, 3.40-5.00 arası yüksek ilginlik seviyesidir.

SAKİ 4: Hiç endişelenmem (1.00-1.79), endileșenmem (1.80-2.59), ne endişelenirim ne endişelenmem - kararsızım (2.60-3.39), endişelenirim (3.40-4.19), çok endişelenirim (4.20-5.00). Buna göre 1.00 ile 3.39 arası düşük ilginlik seviyesi, 3.405.00 arası yüksek ilginlik seviyesidir.

Ölçekte yer alan 4 soru tüketicilerin satın almış oldukları ürünler hakkında yapacakları kişisel yorumları içermektedir. İlginlik kavramının kişisel bir durum olduğu ve bir süreç olduğu düşünüldüğünde satın alma kararı ile ilgili geliştirilen bu ölçeğin çalışma için uygun olduğu belirlenmiştir (Muehling ve diğerleri, 1993, 23-34). Tüketicilerden alınacak cevaplar belirli ürün kategorilerinde yer alan belirli ürünler çerçevesindedir. Bu ürünler Kaller Fay Group ürün genel kategorilerini temsil edebilecek ürünlerdir. Ürünler çerçevesinde alınan yanıtlar değerlendirilmiş olup verilen yanıtların toplam kişi sayısına göre frekans analizi yapılmıștır. Yapılan frekans analizi ile her ürüne tüketicilerin vermiş oldukları cevapların ortalaması alınmıștır. Böylece Krugman'ın (1965) düşük/yüksek ilginlikli modeline göre ürün bazında bir değerlendirme yapılmış, hangi ürünün düşük hangi ürünün yüksek ilginliğe sahip olduğu tespit edilmiştir. Ürün kategorilerinin belirlenmesi yıllık olarak dünya çapında yapılan tüketici araştırmalarında Kaller Fay Group'un kullanmış olduğu ürün kategorisi cetvelinden faydalanılmıştır. Buna göre ürün kategorileri aşağıdaki gibidir:

- Yiyecek

- Eğlence

- İçecek

- Alışveriş Yeri

- Sağlık

- Telekomünikasyon

- Spor/Hobi

- Teknoloji

- Kişisel Bakım

- Otomotiv

- Bankacilık Hizmetleri

- Ev

- Çocuk Ürünleri

- Ev-içi Ürünler

- Tatil

\section{Veri Toplama Aracı ve Örneklem}

Veri toplama aracı olarak anket kullanılmış olup, Google'ın online sunmuş olduğu anket/formlar kullanılmıștır. Anadolu Üniversitesi'nde görev yapan ve farklı birimlerde bulunan, araştırmanın yapıldığı sırada ulaşılan 465 kişiden belirlenen ürünleri satın almış ve internet kullanım düzeyleri ankete cevap verebilecek 
nitelikle olan 100 kişi amaçlı örnekleme tekniği ile belirlenmiş ve ardından veri online olarak toplanmıştır. Evrenin Anadolu Üniversitesi çalışanları olması benzer ürünleri tüketebilecek kişiler olmasından kaynaklanmaktadır. Amaçlı örnekleme, evrenin soruna en uygun bir kesimini gözlem konusu yapmak demektir (Sencer, 1989, 386). Bu bağlamda araştırmaya konu olan ürün ilginliği kavramı hakkında belirlenen tüketiciler satın almış oldukları ürünler hakkında bilgi verebilecek kişiler örnekleme dahil edilmiştir. Alınan örneklemin evreni temsil yeterliği bulunmadığında yeterli bir örneklem belirlemek gereklidir (Bailey, 1987; akt. Balcl, 2005, 91). Yeterli bir örneklem, güvenilir sonuçlar sağlayacak kadar eleman kapsayan örneklemdir (Young, 1968, 324). Bu bağlamda örneklemin çok küçük olması araştırmanın sonuçlarının belirlenen evrene genellenebilmesini güçleştirmektedir. Bundan hareketle, Anadolu Üniversitesi çalışanları bir evren olduğu düşünüldügünde ve literatür doğrultusunda amaçlı örnekleme yöntemi ile örneklem belirlendiği için 100 kişiden alınan yanıtların yeterli olacağı düşünülmüştür (Gay, 1987; akt. Arlı ve Nazik, 2001, 770).

\section{Bulgular}

Anadolu Üniversitesi çalışanlarına Kaller Fay Grup'un tüketici araştırmalarında belirlemiş olduğu ve Krugman'ın yüksek ilginlik/düşük ilginlik modeli bağlamında çeşitli kategorilerde ürün satın alma kararlarına ilişkin sorular sorulmuştur. Çevrim içi anket yöntemi ile toplanan veriler SPSS Statistics 15.0 yazılımı ile frekans analizi tekniği ile analiz edilmiştir. Analiz edilen veriler ışığında kategorilere atanmış ürünler/hizmetler cevaplayıcıların verdikleri yanıtlara göre ortalamaları alınmıștır. Bu alınan veriler Tablo 2'de yer almaktadır.

Tablo 2: Ürün Satın Alma Karar Ölçeğine Göre Tüketici İlginliği

\begin{tabular}{|c|l|l|c|c|c|}
\hline $\begin{array}{c}\text { Sıra } \\
\text { Numarası }\end{array}$ & Ürün Kategorisi & Ürün & $\mathbf{N}$ & $\begin{array}{c}\text { 5 Üzerimden Aldığı } \\
\text { Ortalama Değer } \\
\text { (Mean) }\end{array}$ & İlginlik Düzeyi \\
\hline 1 & Yiyecek & Makarna & 100 & 3,22 & Düşük \\
\hline 2 & Eğlence & Sinema Filmi & 100 & 4,48 & Yüksek \\
\hline 3 & İçecek & Kola & 100 & 3,30 & Düşük \\
\hline 4 & Alışveriş Yeri & AVM & 100 & 2,91 & Düşük \\
\hline 5 & Sağlık & Vitamin Hapı & 100 & 4,06 & Yüksek \\
\hline 6 & Telekomünikasyon & $\begin{array}{l}\text { Cep Telefonu } \\
\text { (smartphone) }\end{array}$ & 100 & 4,63 & Yüksek \\
\hline 7 & Spor/Hobi & Spor Salonu & 100 & 3,85 & Yüksek \\
\hline 8 & Teknoloji & Bilgisayar & 100 & 4,50 & Yüksek \\
\hline 9 & Kişisel Bakım & Şampuan & 100 & 3,86 & Yüksek \\
\hline 10 & Otomotiv & Otomobil & 100 & 4,32 & Yüksek \\
\hline 11 & Bankacılık & Bankacılık & 100 & 4,03 & Yüksek \\
\hline 12 & Ev & Hizmetleri & 100 & 4,56 & Yüksek \\
\hline 13 & Çocuk Ürünleri & Çocuk Bezi & 62 & 3,50 & Yüksek \\
\hline 14 & Ev-içi Ürünler & Mobilya & 100 & 4,10 & Yüksek \\
\hline 15 & Tatil & Otel & 100 & 4,29 & Yüksek \\
\hline
\end{tabular}

Tablo 2'de görülen ürün kategorileri ve ürünler Kaller Fay Grup'un tüketici araştırmalarında kullanmış olduğu genel ürün kategorileri ve ürünlerdir. Tablo incelendiğinde toplamda 15 ürün kategorisi bulunmakta ve bu ürün kategorilerinden sadece "Çocuk Bezi" kategorisine alınan yanıtlar 62 kişiden oluşmaktadır. Bunun 
temel nedeni ise bu kişilerin çocuklarının olmamasıdır. Sonuca yanlış bir etki edeceği düşünüldüğünden bu kişiler dışında kalan cevaplar analiz dışı bırakılmıștır.

Yöntemde belirtildiği üzere bir ürün kategorisine ait bir ürünün tüketici ilginliği bağlamında düşük ya da yüksek ilginliğe dahil olabilmesi için 5 üzerinden almış oldukları değerlerin 1.00 ile 3.39 arasında ise düşük ilginlik seviyesi, 3.40-5.00 arasında ise yüksek ilginlik seviyesi olduğu belirtilmiștir.

Tüm kategoriler değerlendirildiğinde en yüksek ortalama değere ve yüksek ilginliğe sahip ürün telekomünikasyon kategorisi altında yer alan cep telefonu (smartphone) ürünü olduğu görülmektedir. En düşük ortalama değere sahip olan diğer bir deyişle düşük ilginliği olan ürün kategorisi ve ürün ise, alışveriş yeri kategorisinde yer alan AVM’ler olduğu görülmektedir.

\section{Sonuç ve Değerlendirme}

Kaller Fay Grup'un belirlemiş olduğu ürün kategorilerine yönelik olarak Anadolu Üniversitesi çalışanlarına ürün satın alma kararları ile ilgili sorular sorulmuştur. Bu sorular çalışanların hangi ürüne daha çok hangi ürüne daha az ilginlik gösterdiklerini belirlemektedir. Yapılan bu araștırmada da çalışanların yüksek ilginlik gösterdikleri ürünler aldıkları değerlere göre sırasıyla aşağıdaki gibidir:

1. Telekomünikasyon (Cep Telefonu/Smartphone) $-4,63$

2. Ev (Gayrimenkul) - 4,56

3. Teknoloji (Bilgisayar) $-4,50$

4. Eğlence (Sinema filmi) $-4,48$

5. Otomotiv (Otomobil) $-4,32$

6. Tatil (Otel) $-4,29$

7. Ev- içi Ürünler (Mobilya) - 4,10

8. Sağlık (Vitamin Hapları) - 4,06

9. Bankacılık (Bankacılık Hizmetleri) - 4,03

10. Kișisel Bakım Ürünleri ( Şampuan) - 3,86

11. Spor/Hobi (Spor Salonu) - 3,85

12. Çocuk Ürünleri (Çocuk Bezi) - 3,50

Çalışanların düşük ilginlik gösterdikleri ürünler ise aldıkları değerlere göre sırasıyla aşağıdaki gibidir:

1. İçecek (Kola) - 3,30

2. Yiyecek (Makarna) $-3,22$

3. Alışveriş Yeri (AVM Tercihi) - 2,91

$\mathrm{Bu}$ sıralamaya göre çalışanların vermiş oldukları yanıtlar doğrultusunda yüksek ilginlik gösterdikleri ürünlerin daha çok teknoloji tabanlı ve lüks tüketim ürünlerinde olduğu görülmektedir. Yeni olana karşı ilginlik daha yüksek olmaktadır. Ayrıca Maslow'un ihtiyaçlar hiyerarşisine göre tüketime yönelik ürün ilginlikleri zaruri olandan çok zaruri ihtiyaçlar dışı bir yapı sergilediğini görmekteyiz.

Sıralamaya tekrar baktığımızda ilginliği düşük olan ürünlerin içecek, yiyecek ve alışveriş yeri tercihlerinde olduğunu görmekteyiz. Burada farklı gözüken bir detay AVM tercihlerinde kendisini göstermektedir. Bu da tüketicilerin tercihlerinde AVM farklılaşmasının olmadığını bizlere göstermektedir. 
Yapılan bu araştırma ile Krugman'ın 1965 yılında ortaya attığı yüksek/düşük ilginlik modeli, 1989 yılında geliştirilen satın alma kararı ölçeği ile test edilmiş ve günümüz tüketicilerinin ürün kategorilerine göre hangi ürüne karşı düşük hangi ürüne karşı yüksek ilginlik gösterdikleri ortaya konmuştur. Gelecekte yapılacak çalışmalarda, nitel yöntemlerden faydalanılabilir, bu yöntemler ile günümüz post-modern tüketicisinin sadece düşük/yüksek ilginlik değil bunların yanında farklı değişkenlere de olan durumları tespit edilebilir. Derinlemesine görüşme ya da odak grup görüşmeleri ile tüketicilerin bu ürünlere karşı almış oldukları satın alma kararları sorgulanabilir ve böylece tüketicinin rasyonel olmayan yönleri de değerlendirilerek daha detaylı bir çalıșma yapılabilir.

\section{Kaynakça}

Andrews, J., Craig, Srinivas, D. ve Syed, H. Akhter (1990). A Framework for Conceptualising and Measuring the Involvement Construct in Advertising Research, Journal of Advertising, 19(4), 27-40

Antil, H, Jhon (1984) .Conceptualization and Operationalization of Involvement, in NA - Advances in Consumer Research Volume 11, eds. Thomas C. Kinnear, Provo, UT : Association for Consumer Research, 203-209.

Arlı, M. ve Nazik, H. (2001). Bilimsel araştırmaya giriş. Ankara: Gazi Kitabevi.

Balcı, A. (2005). Sosyal bilimlerde araştırma. Ankara: Pegema Yayıncılık.

Bloch, P. H., Sherrell, D. L., ve Ridgway, N. M. (1986). Consumer search: An extended framework. Journal of Consumer Research, 13, 119-26. http://dx.doi. org/10.1086/209052

Houston, M.J. ve Rothschild, M.L. (1978). Conceptual and methodological perspectives on involvement. In: Hunt, H.K. (Ed.), Advances in Consumer Research 5, Ann Arbor MI: Association for Consumer Research, 184-187.

Kaller Fay Group. (2016). Product Category. Erişim: 16.11.2017 https://www. kellerfay.com/the-gender-gap-in-product-category-conversations/

Krugman, H. E. (1965), "The Impact of Television Advertising: Learning without Involvement," Public Opinion Quarterly, 29, 349-356.

Michaelidou, N. ve Dibb C.S. (2006). Product involvement: an application in Clothing. Journal of Consumer Behaviour, 5 (5), 442-453.

Mitchell, A. A. (1979), "Involvement: A Potentially Important Mediator of Consumer Behavior," in W. Wilkie ed., Advances in Consumer Research, Vol. 6, Ann Arbor: Association for Consumer Research, 191-196.

Mittal, Banvari ve Myung-Soo Lee (1989), "A Casual Model of Consumer Involvement", Journal of Economic Psychology, 10 (3), 363-389.

Mittal, Banwari (1995), "A Comparative Analysis of Four Scales of Consumer Involvement", Psychology \& Marketing, Vol. 12 (7), 663-682.

Muehling, D. D., ve Laczniak, R. N. (1988). Advertising's immediate and delayed influence on brand attitudes: Considerations across message-involvement levels. Journal of Advertising, 17(4), 23-34. 
Petty, R. E. ve J. T. Cacioppo (1979), "Issue Involvement Can Increase or Decrease Persuasion by Enhancing Message -Relevant Cognitive Responses," Journal of Personality and Social Psychology, 37, 1915-1926.

Sencer, M. (1989). Toplumbilimlerinde Yöntem. İstanbul: Beta Basım.

Ulusu, Y. (2016). İlginlik. Marmara Üniversitesi Öneri Dergisi. 12 (45), 569-586.

Vaughn, R. (1980). How advertising works: A planning model. Journal of Advertising Research, 20(5), 27-33.involvement construct. Journal of Consumer Research, 12, 341-52. http://dx.doi.org/10.1086/208520

Young, P. V. (1968). Bilimsel sosyal incelemeler ve araştırma (Çev. G. Bingöl ve N. İşçil). Ankara: Ege Matbaası. 